\title{
Primera plana de Billy Wilder. La nostalgia de los periodistas en el exilio
}

\author{
Simón PEÑa FERNÁNDEZ \\ Universidad del País Vasco (UPV/EHU) \\ simon.pena@ehu.es
}

Recibido: 9 de marzo de 2012

Aceptado:22 de octubre de 2012

\begin{abstract}
Resumen
Ya al final de su carrera, Wilder adaptó por tercera vez la clásica obra teatral de Ben Hecht y Charles MacArthur Primera plana. En ella volcó no sólo su habitual causticidad, sino también su propia experiencia personal como reportero en Viena y Berlín durante los años veinte. Esta obra ha construido un influyente retrato de la prensa como una profesión despiadada y sin escrúpulos, cuya redención sólo se produce en su papel de control de un poder político aún más corrupto. Diez años después de la muerte del realizador vienés, su Primera plana perdura como uno de los retratos más emblemáticos de los periodistas en el celuloide.
\end{abstract}

Palabras clave: Billy Wilder, Primera plana, periodismo, cuarto poder

\section{Billy Wilder's The Front Page. The nostalgia of the journalists in exile}

\begin{abstract}
At the end of his career, Billy Wilder filmed the third film adaptation of Ben Hecht's and Charles MacArthur's classic play The Front Page. In this work, along with his customary causticity, he also brought his own experience as a reporter in Vienna and Berlin in the 20s. The Front Page has built an influential portrait of the press as a ruthless profession with no scruples, whose redemption is only possible as a watchdog of an even more corrupt political power. Ten yearst after the death of the viennese director, his Front page lives in our memory as one of the most emblematic portraits of journalists in the cinema.
\end{abstract}

Keywords: Billy Wilder, The front page, journalism, fourth state.

Referencia normalizada: PEÑA FERNÁNDEZ, Simón (2012): "Primera plana de Billy Wilder. La nostalgia de los periodistas en el exilio". Estudios sobre el mensaje periodístico, vol. 18, núm. 2 (julio-diciembre), págs.: 907-924. Madrid, Servicio de Publicaciones de la Universidad Complutense.

Sumario: 1. Una personal obra de encargo. 2. La prensa en el Chicago de los años veinte; 2.1. Hecht y MacArthur, dos periodistas en el exilio; 2.2. El manicomio de la calle Madison; 2.3. Las guerras de circulación. 3. Primera plana de Wilder; 3.1. La herencia de Milestone y Hawks; 3.2. Un tributo a los años veinte; 3.3. Los viejos periodistas; 3.4. Los ardides de Walter Burns; 3.5. La corrupción política y el poder de la prensa. 4. Conclusiones. 5. Referencias bibliográficas.

\section{Una personal obra de encargo}

Durante años, Billy WILDER y su colaborador I.A.L. DiAmOND habían considerado la idea de rodar una película al estilo de comedias clásicas americanas como Una mujer difamada (Jack Conway, 1931), La reina de Nueva York (William A. Wellman, 1931) o Roxie Hart (William A. Wellman, 1942). "Dio la casualidad-declaraba DiAMONDque todas ellas eran películas sobre el mundo del periodismo. Hacía tiempo que nadie filmaba aquel tipo de película" (MCBRIDE, 1974: 212).

La oportunidad les llegó finalmente de la mano de los estudios Universal y la obra teatral Primera plana de Ben Hecht y Charles MacArthur, que ya había conocido dos adaptaciones cinematográficas con anterioridad: la dirigida por Lewis Milestone y 
protagonizada por Adolphe Menjou y Pat O'Brien (Un gran reportaje, 1931), y el clásico de Howard Hawks Luna nueva (1940), con Cary Grant en el papel de Walter Burns y Rosalind Russell como Hildy Johnson.

El promotor de la nueva adaptación fue Paul Monash - guionista televisivo y productor de la exitosa Dos hombres y un destino (George Roy Hill, 1969)- quien tras acudir a una representación teatral de Primera plana en el Old Vic londinense pensó que había llegado la hora de llevar de nuevo a la gran pantalla la obra de Hecht y MacArthur tras más de treinta años desde su última adaptación cinematográfica. "Con el divertimento del Chicago de los años veinte El Golpe (George Roy Hill, 1973) batiendo récords para la Universal y el Watergate convirtiendo a los reporteros en héroes populares modernos, Primera plana tenía todos los números para convertirse en una comedia de éxito" (LALlY, 1998: 440). El film contaba además con el aliciente añadido de reunir otra vez en la gran pantalla a Jack Lemmon y Walter Matthau, la pareja cómica a la que el propio cineasta había dirigido en su primer trabajo cinematográfico conjunto (En bandeja de plata, 1966).

Para Wilder, Primera plana suponía la ocasión de reencontrarse con el éxito de público que se le había negado en sus cuatro anteriores largometrajes, todos ellos filmados con la Mirisch Company y la United Artist. Sin embargo, pese a su interés y a que la historia parecía ajustarse muy bien a su perfil como director, Wilder no fue la primera opción de la Universal para dirigir el proyecto. El ofrecimiento del ejecutivo Jennings Lang para ponerse de nuevo tras las cámaras con casi 70 años sólo le llegó tras la negativa de Joseph L. Mankiewicz (MCBRIDE, 1974: 81)1.

\section{La prensa en el Chicago de los años veinte}

\subsection{Hecht y MacArthur, dos periodistas en el exilio}

En otoño de 1973 WILDER y DIAMOND -también ex periodista- comenzaron a reescribir Primera plana. Pese a no ser el promotor original de la idea, la biografía personal del realizador vienés guardaba muchas afinidades con el argumento de la película, pues la trama se situaba en la misma época en la que, antes de dar el salto al cine, ejerció como reportero en las calles de Viena y Berlín (PEÑA, 2012: 53-124).

Al igual que Wilder y Diamond, Ben Hecht y Charles MacARthur también trabajaron como periodistas en su juventud antes de iniciar su carrera como escritores, en Broadway primero y en Hollywood más tarde. Ambos se habían desplazado a Nueva York por separado a mediados de los años veinte para centrarse en sus respec-

${ }^{1}$ Curiosamente, no era la primera vez que la trayectoria de ambos directores se cruzaba alrededor del periodismo. Durante un corto periodo de tiempo -entre septiembre y diciembre de 1928 - tanto Wilder como Mankiewicz ejercieron como periodistas en Berlín. Mientras Billy trabajaba como reportero y escribía sus primeros guiones cinematográficos, Joseph llegó como ayudante del corresponsal del Chicago Tribune en la capital alemana, desde donde también informó para la revista Variety. Mankiewicz compaginó las labores periodísticas con las de traductor de intertítulos de las películas que se exportaban a Estados Unidos. Su experiencia berlinesa se asemeja en cierto modo a la de Wilder, ya que la calificaba como "una intoxicación absoluta de teatro, excitación, glamour y sexo" (HEREDERO, 1985: 31). 
tivas carreras literarias tras haber coincidido como reporteros en las calles de Chicago durante más de una década. En su autobiografía $A$ Child of the Century, HECHT recordaba que el pilar de su amistad fue su mutua obsesión por sus años de juventud como periodistas:

"For twenty-five years we assisted each other in behaving as if these pasts had never vanished. We remained newspaper reporters and continued to keep our hats on before the boss, drop ashes on the floor and disdain all practical people" (НеCHT, 1954: 391).

En el epílogo de Primera plana, los autores señalan que su impulso inicial fue el de escribir una obra que recogiera el desprecio que albergaban por la que había sido su profesión, partiendo del sentimiento de superioridad intelectual que les llenaba en ese momento. Sin embargo, a medida que la escribían, se dieron cuenta de que su actitud era falaz, pues ambos añoraban los años que habían pasado en las salas de prensa. La obra terminó siendo un cariñoso homenaje a su antigua profesión y a sus compañeros, y también un tributo a la ciudad de Chicago. Escribir Primera plana, confesaban finalmente los autores, les había ayudado a comprender que, en realidad, no eran dos dramaturgos o intelectuales, sino simplemente dos periodistas en el exilio (HECHT y MACARTHUR, 1928: 187-188).

A pesar de que en sus inicios la obra se presentó como una sátira sobre el mundo de la prensa, la correspondencia con sucesos y periodistas reales revelan que el componente ficticio de la historia es menor del que pudiera parecer a primera vista (HILTON, 2002). El retrato, aunque sin duda distorsionado en favor de la comicidad, no envidia en nada a algunas de las situaciones reales que protagonizaron los periodistas de la época: "The premise then -the scaped cop killer, the loss of a good reporter to pastures greener with dollar bills, the cut-throat newspaper rivalry in which both readers and accuracy were lost sight of -had its basis in the cumulative experience of the authors" (FETHERLING, 1977: 72).

La relación entre Hildy Johnson y Walter Burns -el director del Examiner y su periodista estrella- se inspira directamente en los años en los que Charles MacArthur trabajó bajo las órdenes de Walter Howey, su director en el Herald and Examiner de William Randolph Hearst. Pero, en palabras de (Неснт, 1957: 49), rebajaron el tono de los sucesos, porque reproducir lo que ocurría entre las paredes de la redacción-que era conocida como 'el manicomio de la calle Madison'- habría sido demasiado espeluznante para los espectadores de la época.

También MacArthur consideraba que la obra era sólo una muestra edulcorada del mundo de la prensa que habían conocido en Chicago y que se quedaba corta en la descripción de periodismo sin escrúpulos que todos ellos habían practicado: "When the play opened on Broadway, a newspaperman questioned its authenticity and also complained that no mother would ever let her son be a newspaper man if she saw the way the editor and reporters carried on in the play. I replied that the play was an understatement of that era"'2. El propio Wilder se sumaba también a esta visión sobre los des-

${ }^{2}$ Declaraciones recogidas en el obituario sobre su antiguo director, Walter C. Howey. En: The New York Times, 22 de marzo de 1954, p.27. 
enfrenados tiempos pasados y reconocía que difícilmente podría reflejar en la película toda su experiencia personal como periodista en Viena y Berlín: "Hardly, it would be very censorable even today" (MCBRIDE, 1974: 81).

Buena parte de esos excesos se debieron a Walter Crawford Howey, jefe de MacArthur y director del Herald and Examiner entre 1917 y 1922, famoso por su celo y sus métodos para obtener informaciones. Como hombre de confianza de Hearst, se convirtió en una leyenda viva del periodismo de Chicago en una época en la que la competencia entre los diarios de la ciudad era despiadada.

Su etapa como director del Herald and Examiner está cuajada de ejemplos de sus poco ortodoxos métodos, a medio camino entre la realidad y la leyenda. Dentro de las prácticas habituales del diario se incluía, por ejemplo, la de tener en nómina a telefonistas de la policía para adelantaran datos sobre los sucesos, dentro de una extensa red de informadores en la que se incluían, entre otros, una enfermera en cada hospital, un botones en cada hotel y un policía en cada barrio (MURRAY, 1965: 39).

Según Ben Hеснт, Howey también guardaba en el cajón de su escritorio las cartas de dimisión de media docena de los principales funcionarios públicos de la ciudad; cuando el diario descubría que un alto cargo estaba implicado en algún asunto turbio, el director se comprometía a silenciar el suceso a cambio de una renuncia firmada por el implicado, quien se mantenía en su cargo siempre dispuesto a colaborar con el $\mathrm{He}$ rald and Examiner en lo que fuera necesario. La práctica de retener la información comprometedora sobre fraudes y corruptelas se extendía desde políticos hasta banqueros o industriales, a quienes Howey hacía entender que publicar anuncios en su diario era el mejor modo de defender sus intereses. Casi todos ellos cedían al chantaje y se convertían en generosos compradores de espacios publicitarios en el diario de $\mathrm{He}-$ arst en Chicago (HеCHT, 1957: 52).

Estas prácticas guardan, desde luego, una gran similitud con las que desarrollaba, aproximadamente durante la misma época, Imre Békessy en los vieneses Die Stunde y Die Bühne para los que Billy Wilder trabajó entre finales de 1924 y mediados de 1926. Las acusaciones de chantaje y corrupción que arreciaron contra el editor de origen húngaro durante esos años, en las que el futuro cineasta ocupó un papel secundario como uno de los reporteros que participó en el denominado 'impuesto de los cafés' -consistente en amanazar con publicar informaciones negativas sobre los establecimientos hosteleros vieneses si no incluian publicidad en las páginas de las publicaciones de Kronos Verlag- sin duda provocaron que los sucesos recogidos en la obra de Hecht y MacArthur, pese a la distancia, le resultaran muy cercanos a Wilder (HuTTER, 2002: 23).

\subsection{EI manicomio de la calle Madison}

El enloquecido Herald and Examiner de Primera plana poco tiene que envidiar al diario en el que se inspira, el American de Chicago - y sus herederos ${ }^{3}$ - probablemente

${ }^{3}$ La edición matutina del American salió a la calle el 2 de mayo de 1902 con el nombre de Chicago Examiner, con el objetivo de competir con el Tribune. Los dos diarios, prácticamente siameses, compartían casi todo, menos la redacción. El 2 de mayo de 1918 se fusionó con 
el periódico más agresivo del polémico magnate de la prensa amarilla William Randolph Hearst.

A diferencia de San Francisco y Nueva York, donde había tomado como base diarios ya existentes, Hearst lanzó a la calle el vespertino American tras construirlo desde la nada en un tiempo récord de seis semanas. Cuando sus aspiraciones presidenciales se mantenían aún intactas y con el objetivo de reforzarlas, Hearst decidió en 1900 extender su cadena de diarios a Chicago, por entonces la segunda mayor ciudad de Estados Unidos. El presidente republicano McKinley se presentaba a la reelección y el partido demócrata buscaba aumentar las opciones de su candidato Bryan con un diario que defendiera sus intereses en la región de los grandes lagos. A finales de mayo, El Jefe encargó a Arthur Brisbane y Solomon Carvalho, sus hombres de confianza en el Journal, la creación de un diario en Chicago antes del 4 de julio. A golpe de talonario, adquirieron el vetusto pero enorme edificio de la calle Madison, en el que montaron la redacción y la rotativa, y contrataron a un ejército de periodistas, tipógrafos, editores, ilustradores y distribuidores (NASAW, 2001: 154).

El American salió a la calle el 2 de julio de 1900, tres días antes de la nominación de Bryan como candidato del partido demócrata a las elecciones presidenciales. Rápidamente se convirtió en el más amarillista de todos los diarios de Hearst, que desde sus inicios se centró en una sensacional cobertura de los crímenes, favorecida por el propio ambiente reinante en la ciudad (Pizzitola, 2002: 79).

En la redacción el trabajo se desarrollaba de forma febril. Se publicaban ediciones prácticamente cada hora, en las que se cambiaban los titulares y las entradillas de las páginas 1,3 y 5 -hubiera datos nuevos o no- con ediciones extra hasta incluso después de medianoche (MurRaY, 1965: 37). El American era también el único diario de Chicago que, además de las ediciones matutinas y vespertinas, se publicaba también los domingos (SALISBURY, 1908: 152).

Al margen del ajetreo que provocaba sacar a la calle múltiples ediciones, la sede del diario pasó a ser conocida como el 'manicomio de la calle Madison' por el enloquecido ritmo de trabajo y el trasiego de trabajadores producido por las constantes contrataciones y despidos. En sus primeros 37 meses de existencia, la edición local del American llegó a alcanzar la extraordinaria cifra de 27 responsables diferentes (MURRAY, 1965: 12).

Sobre su experiencia como reportero en el diario de Hearst en Chicago, William SALISBURY describe en su autobiográfico Career of a Journalist (1908) el frenesí y la presión constante que se vivía en la redacción, en la que los despidos eran costantes. La presión ejercida sobre los reporteros para que publicaran "historias" y no "hechos" distorsionaba los sucesos de tal modo que, en ocasiones, ni los propios autores reconocían sus noticias una vez publicadas. En su obra, el periodista estadounidense también denunciaba que el American realizaba campañas de hostigamiento contra las

el Chicago Record-Herald y se convirtió en el Herald and Examiner, el diario en el que Hecht y MacArthur sitúan la trama de Primera plana. El Record-Herald vivía un declive, pero contaba con una valiosa suscripción a la franquicia de Associated Press, vetada a los diarios de Hearst (Hilton, 2002: 60). 
grandes corporaciones, que cesaban en el momento en el que éstas comenzaban a anunciarse en el diario (SALISBURY, 1908: 196).

A Wilder, desde luego, algunas de las denuncias de SALisBuRY le habrían resultado muy familiares, pues su Career of a Journalist contiene muchas afinidades con la obra-denuncia El revólver de Békessy (1926) de su antiguo colega en Die Stunde Ernst Spitz. Su antiguo compañero de redacción, además, no sólo criticaba las prácticas chantajistas de Imre Békessy, sino que afeaba la actitud del por entonces joven reportero Billie Wilder por participar en la extorsión informativa a los establecimientos hosteleros vieneses y por dedicarse "al comercio y la distribución de anécdotas inventadas” (HutTER y KAMOLZ, 1998: 69).

\subsection{Las guerras de circulación}

La agresividad y violencia que impregnaban la vida diaria y las páginas de los periódicos cautivaron a los jóvenes Ben HechT y Charles MACARTHUR, que recordaban con nostalgia sus años de trabajo como periodistas en Chicago. Consideraban a la ciudad su particular reino de las hadas, al que les gustaba referirse como Ávalon ${ }^{4}$ (HECHT, 1957: 134). Para un reportero de sucesos, desde luego, pocos lugares podían ofrecer más alicientes que una ciudad que lideraba -y lo sigue haciendo- los índices de criminalidad entre las grandes urbes de Estados Unidos.

Pero si durante los años veinte, época en la que se sitúa la trama de Primera plana, la rivalidad entre los siete grandes diarios que se publicaban en el área metropolitana de Chicago era feroz, durante la década anterior había llegado a adquirir tintes criminales y sangrientos. La prensa no sólo no había sido ajena a la violencia que reinaba en la ciudad, sino que había participado activamente de ella. Tras el desembarco de Hearst en la ciudad, primero con el vespertino American en 1900 y más tarde con el matutino Examiner, las amenazas y palizas ocasionales a los vendedores, las peleas entre los distribuidores y la destrucción de ejemplares del diario rival, sucesos ocasionales hasta aquel momento, se convirtieron en la muestra menos agresiva de las tácticas utilizadas en una guerra de ventas a gran escala.

Inicialmente, dentro de las salvajes disputas entre los periódicos que se editaban en la ciudad, en especial entre los matutinos Tribune y Examiner, los diarios contrataron a matones profesionales para que amedrentaron a los vendedores y suscriptores de las cabeceras rivales mediante amenazas y palizas (KeEFe, 2003: 69-73). Los sicarios conminaban a los quiosqueros a que exhibieran únicamente el diario para el que trabajaban y a que guardaran los demás en el interior y los vendieran sólo a quienes los pidieran expresamente por su nombre. Además, argumentaban que esta técnica incre-

${ }^{4}$ La isla de Ávalon es el reino de las hadas de las leyendas artúricas. También es el lugar en el que Morgana sana a Arturo de las heridas de muerte que recibe en la batalla de Camlann y desde el que éste realiza su mesiánico regreso como rey de Inglaterra. Godofredo de Monmouth la cita en su Historia regum Britanniae (1136) y en Vita Merlini (1150) la describe como 'Insula pomorum', el lugar en el que los manzanos dan fruta durante todo el año. (V. 'Avalon'. En: Encyclopcedia Britannica. http://www.britannica.com/EBchecked/topic/45381 /Avalon). 
mentaría las ventas de ese diario y les instaban a que aumentaran su pedido de ejemplares. El quiosquero, naturalmente, debía pagar por todos los diarios que encargaba, independientemente de que los que llegara a vender o no, lo que gráficamente se expresaba como "sell'em or eat'em". A los vendedores que no se plegaban a estas exigencias los matones les propinaban una paliza (MURRAY, 1965: 43).

Los incidentes se multiplicaron. En los años más cruentos de esta guerra de ventas -entre 1913 y 1917 - fueron asesinados 27 vendedores y distribuidores de diarios, a los que se sumaron centenares de heridos. Algunos de los principales gánsteres de la época de la Prohibición se curtieron en las calles de Chicago como sicarios en esta lucha por lograr alcanzar el mayor número de ventas. Entre ellos se encontraba Dean O'Banion, quien alcanzó la celebridad por sus enfrentamientos con la banda de Capone y que, como empleado del American y el Herald and Examiner de Hearst, coaccionaba a vendedores y asaltaba camiones de reparto del Tribune (Lesy, 2007: 204-205)

Crimen y periodismo parecían unidos con tal naturalidad que en 1920 el alcalde William Hale Thompson nombró jefe de policía a Charles Fitzmorris, cuya única cualificación para el trabajo consistía en haber sido redactor del American (LESY, 2007: 261). El asesinato de Alfred Jake Lingle y el posterior descubrimiento de su doble vida como reportero, gánster y "conseguidor de favores" tampoco ayudaron a mejorar la imagen de los periodistas. La reputación de la prensa de Chicago quedó manchada y surgieron dudas sobre si otros periodistas se habían pasado también al chantaje sistematizado (TeEL, 2006: 140). En este contexto, no resulta extraño que Hecht y MACARTHUR presentaran al personaje del indisimulado gánster Diamond Louie como sombrío brazo ejecutor de las maquinaciones de Walter Burns en Primera plana: "We called them badland in print, but poked around in them as happily as if they were our grandmother's attic" (HECHT, 1957: 12).

La llegada de la Primera Guerra Mundial y la entrada de Estados Unidos en la contienda, sin embargo, propició que los diarios vendieran tantos ejemplares como podían publicar y cambió de manera radical el curso del interés informativo, por lo que la prensa abandonó estas prácticas violentas. La llegada de la Prohibición en 1920 propició, además, que los matones cambiaran con naturalidad de área de extorsión y comenzaran a dedicarse al tráfico y la venta de alcohol.

\section{Primera plana de Wilder}

\subsection{La herencia de Milestone y Hawks}

En diciembre de 1927, pocas semanas después de que Hecht y MacArthur terminaran de escribir Primera plana, el exitoso productor Jed Harris, que había encadenado cuatro grandes éxitos en Broadway entre 1926 y 1928, compró sus derechos y le encargó la dirección a George S. Kaufman. La obra se estrenó en el Times Square Theatre de Nueva York el 14 de agosto de 1928 y logró un éxito rotundo en plena época dorada de Broadway. Durante su primera temporada se realizaron 276 representaciones con

5 O'Banion probó incluso fortuna con algunos relatos literarios y llegó a inscribirse en el censo de 1920 como "reportero de diario" (KeEFE, 2003: 77). 
Lee Tracy como Hildy Johnson y Osgood Perkins en el papel de Walter Burns. La polémica sobre el lenguaje utilizado persiguió a la obra, provocando que la policía de Nueva York tratara incluso de detener a los actores tras una de las funciones. Cuando se representó en Toronto 1932, la orquesta tocaba por encima de los diálogos de los actores en los pasajes más procaces. La frase que centró las iras de los defensores del decoro no era otra que aquella con la que caía el telón: "The son of a bitch stole my watch" (FETHERLING, 1977: 71).

Si el lenguaje obsceno y la célebre frase final causaron controversia en las representaciones teatrales, cuando la obra saltó a la gran pantalla desaparecieron sin dejar rastro alguno durante más de cuarenta años, hasta que Wilder pudo realizar una adaptación más fiel aprovechando la relajación de las normas autorreguladoras.

El rotundo éxito en Broadway provocó que el salto de los escenarios al celuloide no se demorara y la United Artists compró los derechos para el cine en 1930. En una época en la que los estudios adquirían con ansiedad cualquier obra que pudiera llevarse a la gran pantalla como película sonora, Primera plana brillaba como una elección natural por sus electrizantes diálogos y su abundante acción. Howard Hughes adquirió los derechos de la obra teatral a Jed Harris por 125.000 dólares y encargó el guión a dos ex periodistas, Charles Lederer y Bartlett Cormack, mientras que dejó la dirección en manos de Lewis Milestone, que acababa de cosechar un rotundo éxito -incluidos los Óscar a la mejor película y al mejor director- por su adaptación de la obra antibélica de Erich Maria Remarque Sin novedad en el frente (1930).

Un gran reportaje (1931) siguió el original teatral con gran fidelidad, aunque se tomaron algunas cautelas a la hora de referirse a personas o instituciones reales. "The script was little changed from the original excerpt insofar as it was subservient to Hollywood's own moralistic punctilios. It was not so much an adaptation for the screen as an adjustment" (FetherLING, 1977: 82). El icono de la elegancia de la época, Adolphe Menjou, interpretó a Walter Burns, mientras que Pat O’Brien encarnó a Hildy Johnson.

La adaptación de Milestone estableció algunas pautas seguidas en todas las versiones posteriores, como la inclusión de Walter Burns desde el mismo inicio de la película o la ampliación del área de acción a otros lugares, como la propia redacción del diario, que se muestra en un largo plano secuencia inicial. También incluía el inicio, que Wilder recupera para su adaptación, en el que los guardianes prueban el patíbulo con sacos y los periodistas, que están jugando a las cartas, se quejan de que el ruido no les deja trabajar, así como la escena en la que el psiquiatra recrea el tiroteo con la pistola del sheriff, sólo aludida en la obra. Wilder reconocía su deuda con la versión de Milestone, a la que de todos modos consideraba muy condicionada por las muy crudas condiciones del incipiente cine sonoro (MCBRIDE, 1974: 81).

Diez años después, Primera plana se convirtió de la mano de Howard Hawks en uno de los ejemplos más clásicos de las screwball comedy de los años cuarenta. En Luna nueva, la obra de Hecht y MacArthur sufrió una profunda transformación hasta convertirse en una comedia romántica gracias a la conversión de Hildy (Rosalind Russell) en mujer, y para colmo, ex esposa de Burns (Cary Grant). Completaba el trián- 
gulo amoroso el atolondrado prometido de la periodista, interpretado por Ralph Bellamy ${ }^{6}$ (Dick, 1996: 116).

El realizador vienés guardaba buenas palabras para Luna nueva -no en vano había aprendido los entresijos del oficio de director junto a Howard Hawks durante el rodaje de Bola de fuego (1941) - pero consideraba que no se ajustaba al espíritu de la obra original que él quería recuperar, pues Cary Grant ponía más énfasis en recuperar a Rosalind Russell como ex mujer que como reportera:

"It was very well done, naturally -señalaba Wilder-, since Hawks is a very good comedy director, but it was not The Front Page by Hecht and MacArthur. It was more The Awful Truth [La picara puritana, Leo McCarey, 1937], when Irene Dunne is going to marry Ralph Bellamy and she used to be married to Cary Grant, that sort of thing" (McBRIDE, 1974: 83).

\subsection{Un tributo a los años veinte}

Frente a la indeterminación temporal de la obra original y de las dos adaptaciones cinematográficas previas, en las que no se precisaba la fecha exacta en la que sucede la acción, WiLDER y DiAmOND situaron su Primera plana el 6 de junio de 1929 y ampliaron el área de los sucesos mencionados, que pasaron de Chicago y sus alrededores a repasar toda la historia de Estados Unidos. El retraso en el momento en el que se sitúa la acción no buscaba precisar las referencias históricas existentes ni eliminar los anacronismos de la obra teatral original -pues siguen existiendo y se incurre en varios nuevos-sino que, más bien al contrario, les permitió inundar los diálogos de alusiones a personajes y sucesos históricos de la década de los veinte fácilmente identificables para los espectadores de los setenta y poder así realizar un tributo a aquella América a través de sus momentos más emblemáticos (PEÑA, 2012: 215-222). Tal y como señala Richard ARMSTRONG (2004: 124), "in style and spirit seems to collapse both prewar decades into one recollection".

Esta añoranza incluye por supuesto un afectuoso retrato de la prensa de los años veinte, época en la que un joven Billie Wilder pateaba las calles de Viena y Berlín

${ }^{6}$ Con posterioridad a la versión de Wilder, Primera plana ha conocido una cuarta y, hasta el momento, última adaptación cinematográfica: Interferencias (Ted Kotcheff, 1988). El film, ambientado en el mundo de la televisión, sigue la estructura de comedia romántica de Luna nueva, con un triángulo en el que Burt Reynolds interpreta al director de la SNN, Kathleen Turner a su periodista estrella y Christopher Reeve al engolado prometido de ésta. Pese a no contar con las limitaciones autorreguladoras que sufrieron las adaptaciones previas, el film pierde buena parte de su carácter irreverente. Una trama criminal mucho más plana y melodramática penaliza algunos de los aciertos del film: Ike Roscoe (Henry Gibson) ha sido condenado a la silla eléctrica por asesinar a un policía, que en realidad también era el traficante al que su hijo compraba la droga, el día en el que éste se mata por accidente por estar colocado. Su particular protectora ya no es prostituta, sino su abogada Pamela Farbrother. Incluso llega a mostrarse un primer intento fallido de ejecución y a la policía abriendo fuego contra el escondrijo de Roscoe. En lo periodístico, el film añade a la obra original la rivalidad entre los periodistas televisivos y los de la prensa. 
como reportero. Ya desde el mismo inicio de la película, las imágenes que acompañan a los títulos de crédito al trepidante ritmo del Front Page Rag de Billy May describen visualmente el proceso de impresión de un diario. Una caja con la cabecera del Chicago Examiner adornada con un águila, emblema identificativo de los diarios de $\mathrm{He}$ arst, abre la película y en poco más de dos minutos y medio, el comienzo de Primera plana ha mostrado con precisión la producción de un diario de principios del S.XX, desde que comienza a componerse la primera página hasta que los ejemplares salen de la rotativa.

Este comienzo, más convencional y aséptico, sustituye al recogido en el guión original, muy similar en su planteamiento al prólogo que el director ya utilizó en La tentación vive arriba. Si en aquél una voz en off comparaba cómicamente el inicio de las vacaciones estivales en Manhattan con las costumbres de los indios que habitaron previamente la isla, en la versión inicial del guión de WILDER y DiAMOND se confrontaban los piadosos inicios de la imprenta de Gutemberg con los estruendosos titulares con los que los diarios inundaban las calles de Chicago durante los años veinte (WILDER Y DIAMOND, 1974: 1):

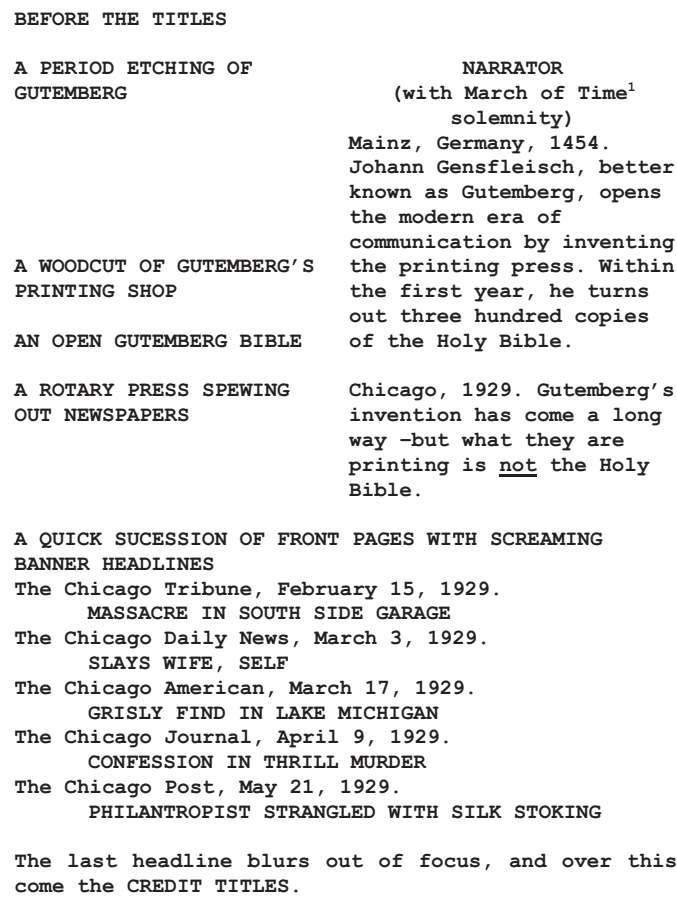

7 The March of Time, el noticiero cinematográfico de la empresa editora de la revista Time, se exhibió en las salas de cine entre 1935 y 1951. La resonante locución de Westbrook Van Voorhis, quien también participaba en la edición radiofónica del noticiero, imprimía a las noticias un tono dramático y sepulcral que le hizo merecedor del apelativo 'Voice of Doom' (FIELDING, 1957: 354). 
Los motivos por los que no se llegó a utilizar este inicio y se optó por uno más convencional son desconocidos, pero por su característico tono corrosivo no cabe duda de que se trataba de una genuina aportación de Wilder y Diamond que se habría ajustado muy bien al tono general del film y al retrato de la prensa de la época.

Wilder compartía el retrato sobre el periodismo que ofrecía la obra teatral y lo hacía suyo, con la intención de recrear, según confesaba a Cameron Crowe (2000: 243), la sensación de lo que era ser periodista. Primera plana combina una mirada dura, con desdén hacia la inocencia sentimental, con una visión romántica y de forajido. En palabras de EHRLICH (2006: 23), la obra muestra una terrible ambivalencia sobre la prensa - un gremio de dudosa reputación-, la cultura de masas y las virtudes de la clase media, aunque al final se convierta en un cariñoso homenaje al periodismo y al modo de vida americano.

"En aquellos días -recordaba Wilder- un periodista era una mezcla de detective privado y poeta. Si eras bueno, podías mejorar la historia; te sentías como un inventor, un descubridor, un explorador, un dramaturgo.... Dabas rienda suelta a lo que había en tu interior: la historia comenzaba con algo bastante simple y tú la convertías en Los tres mosqueteros. Además, estaba la dedicación a tiempo completo -la noción de una familia era imposible para un lobo solitario-, y la camaradería y la rivalidad en la sala de prensa... Los reporteros solían tener problemas o colaborar con la policía, no había término medio. Como demostramos en Primera plana, la policía tiene la tendencia a proteger a los culpables" (SAYRE, 1974: 8, citada por LALLY, 1998: 443).

Entre las múltiples referencias periodísticas, WILDER y DiAMOND también rememoran en su Primera plana algunos hitos periodísticos de la época, como la publicación de la imagen en portada la ejecución de Ruth Snyder en el New York Daily News en enero de 1928 -tomada por el fotógrafo Tom Howard con una cámara atada al tobillo (EMERY y EMERY, 1992:283)-e incluyeron incluso guiños al Watergate, pues la película se estrenó sólo cuatro meses después de la dimisión de Richard Nixon.

\subsection{Los viejos periodistas}

En su cariñoso y nostálgico homenaje a los años veinte, Wilder y Diamond tampoco olvidaron recordar a varios de los periodistas más célebres de la época. Algunas de estas menciones, lamentablemente, se pierden en la versión doblada al castellano. Así ocurre con Heywood Broun y H.L. Mencken, a los que Walter Burns evoca para motivar a Hildy mientras éste redacta la noticia sobre la captura de Earl Williams por parte del Chicago Examiner. Los periodistas citados, desde luego, ocupaban una posición bien distinta a la que podría aspirar un simple reportero de sucesos de Chicago y el comentario adquiere en boca de Burns, cómo no, una connotación profundamente sarcástica. Los guionistas también incluyeron una mención-homenaje repleta de sorna dedicada al propio Ben Hecht.

Pese a la ausencia de referencias explícitas, también planea a lo largo de todo el film la alargada sombra del William Randolph Hearst, la ineludible y extremadamente controvertida figura periodística de la prensa estadounidense de comienzos del S. XX y dueño del Examiner para el que trabajan Burns y Johnson. Pese a su apabullante presencia y poder en la opinión pública de la época, The Chief sólo recibe dos men- 
ciones indirectas que aluden a su célebre amante, la actriz Marion Davies, y al castillo de San Simeón, el palacio que el magnate de la prensa poseía en California, también reccordado como el Xanadú que tan sombríamente retrató Orson Welles en Ciudadano Kane (1941).

Wilder y Diamond también devolvieron al personaje de McHugh el nombre original del periodista real del Chicago American en el que se inspiró. Esta identificación refuerza el vínculo de la ficción con los reporteros auténticos en los que se basa en la obra. Al margen de la pareja protagonista, otros personajes de Primera plana conservan los nombres auténticos de las antiguos compañeros de sala de prensa de Hecht y MacArthur, como Murphy del Evening Journal o Duffy del Herald and Examiner, mientras que en otros alteran ligeramente su grafía o son una amalgama de los rasgos de varios de ellos (HiLton, 2002).

Por encima de las referencias existentes, el esfuerzo de Wilder y Diamond por reforzar el enfoque periodístico de la obra se aprecia con especial nitidez en la redefinición que realizan de los personajes. En esta redefinición, el realizador vienés prescinde en su versión de Primera plana de cuatro personajes secundarios con cierta presencia en la obra original que no eran periodistas: el gánster Diamond Louie, el policía Woodenshoes Eichorn, la Sra. Grant -la madre de Peggy- de la mujer del periodista Herman Schlosser. De todas ellas, la supresión más significativa, al menos en lo referido a su tiempo de presencia en escena, corresponde al personaje de Diamond Louie, el matón contratado por Burns como ayudante de distribución del diario para el North Side de Chicago y que ejerce de brazo ejecutor de todas sus maquinaciones a lo largo de la trama (HeCHT y MACARTHUR, 1928: 77-79). Su presencia en la obra teatral no puede calificarse, desde luego, de casual, pues respondía con precisión histórica a la guerra de distribución que entablaron, entre otros, el American y el Tribune a principios de la década de 1910. Tanto Milestone como Hawks habían mantenido al matón en sus adaptaciones, y el segundo, incluso, lo acompañó de una ayudante. La adaptación de Wilder, por el contrario, rehuye mencionar estas prácticas y la desaparición del gánster centra la trama en su enfoque más profesional y pule algunas de las aristas más ásperas del retrato que realizaban HECHT y MACARTHUR.

En el capítulo de las incorporaciones, Wilder y Diamond refuerzan el papel de Duffy, el hombre de confianza de Burns en la redacción del Examiner, que en la obra teatral original no tenía ninguna línea de diálogo ni salía en escenak, pues se trataba simplemente del interlocutor a quien se dirigían los periodistas del Examiner cuando telefoneaban a la redacción del diario.

Pero, sin duda, la incorporación más significativa introducida por Wilder y Diamond en la sala de prensa de los tribunales de Chicago es la del novato Rudy Keppler como el bisoño periodista con el que Walter Burns trata de reterner a Hildy y despertar sus celos profesionales. Su inclusión rellena también una falla dramática relevante en la obra original, pues hubiera sido impensable que un diario como el Herald and Examiner no enviara a nadie a cubrir la ejecución después de que Hildy se hubiera despedido.

Pero, ante todo, Rudy Keppler encarna el contraste entre el modelos de los viejos reporteros callejeros y autodidactas, ya en extinción en el momento en el que se escribió la obra, y los periodistas con estudios universitarios. En este cambiante entorno 
profesional, Wilder toma partido de forma radical y contribuye al desdén de la obra original por la formación universitaria con esta personal contribución que ridiculiza en todos los aspectos a esta nueva generación de reporteros cuya formación, lejos de ser un objeto de reconocimiento o respeto, será constantemente despreciada y ridiculizada por sus colegas. En manos de WILDER y DIAMOND, el novato reportero se muestra crédulo ante las explicaciones de las corruptas autoridades políticas, no sabe calibrar el verdadero interés de los sucesos y se orina encima cada vez que escucha disparos.

\subsection{Los ardides de Walter Burns}

Frente a la ingenuidad e incapacidad de Rudy Keppler, en la Primera plana wilderiana resplandece de manera aún más intensa la figura de Walter Burns como despiadado director carente de escrúpulos cuya obsesión por vender el máximo número de ejemplares le lleva a pisotear todos los principios éticos existentes. El catálogo de recursos periodísticos deontológicamente reprochables de los que hace gala la encarnación por excelencia del cinismo profesional parece prácticamente ilimitado.

Así, el intento de sacar una fotografía de la ejecución con una cámara atada al tobillo, a imagen y semejanza del caso de Ruth Snyder, constituye sólo la primera muestra de una larga lista de tretas que evidencian una mentalidad en la que cualquier recurso es bueno si permite vender más diarios. Ante Peggy, se hace pasar por inspector de policía para convencerla de que no se case con Hildy, al que hace pasar por un enfermizo exhibicionista; para desembarazarse de Bensinger, en cuyo escritorio ocultan al huido Williams, le hace creer que lo contrata para el Examiner a cambio de un excelente salario y le hace despedirse del Tribune; intenta sacar el mueble del mismísimo edificio de los juzgados con el reo dentro y la ayuda de una polea y seis operarios $^{8}$; envía al inexperto Keppler a cubrir la ejecución para despertar los celos profesionales de Hildy; contrata a una mujer y a sus hijos para que frustren la salida de Hildy hacia Filadelfia haciéndose pasar por la familia a la que abandona; o le regala a su reportero estrella su reloj, sólo para poner una denuncia contra él. Su capacidad improvisadora se antoja inagotable, pues su imaginación tiene una respuesta para cualquier giro que se produzca.

Pese a su indudable comicidad, reforzada por la excelente interpretación de Walter Matthau, su retrato resulta en el fondo mucho más demoledor que el del agresivo y despiadado Chuck Tatum El gran carnaval, pues mientras éste último encarna un delirio individual provocado por un afán de reconocimiento que le conduce a llevar al extremo las prácticas sensacionalistas, Primera plana refleja un proceder institucionalizado, un modo de entender el periodismo extensible a todos los miembros de la sala de prensa (COLPART, 1983:110).

Walter Burns carece de un antagonista moral en Primera plana, aunque Hildy parezca más sensible hacia los problemas de los demás que su jefe. En el fondo, eso sí, el mismo espíritu del 'todo vale' se apodera de sus actos. Para garantizarse la exclu-

${ }^{8}$ En la obra teatral original, en un alarde de recursos que roza el delirio, Walter Burns incluso llega a especular con que la sociedad histórica de Chicago nombre el mueble patrimonio histórico y posteriormente prender fuego al edificio, para que lo saquen los propios bomberos. 
siva, trata de despistar a sus compañeros de sala de prensa, que rápidamente se percatan del truco, pues le recuerdan cómo les mintió el día de la matanza de San Valentín: "De pillo a pillo, es el oficio", replica Hildy, que en la versión original se convierte en un más enfático "dog eat dog". El reportero también se atribuye incluso haber escrito el diario de Roxie Hart - en homenaje a la obra teatral Chicago (1926) de Maurine Dallas Watkins-, una confesión que no puede considerarse extraña en la prensa de la época, en especial en el Herald and Examiner. En los casos en los que estaban involucradas mujeres jóvenes y atractivas, Walter Howey insistía en que debían seguirse tres directrices: primero, lograr la historia; segundo, encontrar una fotografía; y tercero, 'producir' un diario (HEARST y CASSERLY, 1991: 202).

Como es obvio, el resto de los reporteros de la sala de prensa se incorpora con naturalidad al modelo encarnado por Burns y Hildy, en especial en tres momentos de la película. Al principio, mientras se informa sobre las últimas horas de Williams, en las que se copian unos a otros las informaciones; a su regreso del tiroteo, del que cada uno realiza un enfoque más pintoresco, y finalmente en la captura de Williams, en el que la detención del condenado a muerte adquiere sensacionales y variados detalles según quién realice la crónica telefónica.

En la Primera plana de Wilder, la visión romántica de la profesión, el nostálgico recuerdo a los tiempos que no han de volver, construye un retrato de los reporteros a medio camino entre la realidad y la leyenda.

"Para Hecht y MacArthur, estos periodistas de cinismo inoxidable y audacia sin límites, enamorados de la aventura cotidiana, capaces de jugarse el cuello por un buen titular, ya habían comenzado a dejar de existir cuando Primera Plana fue concebida y estrenada. Las acotaciones de la obra presentan una visión casi elegíaca de estos supervivientes de una edad dorada, representante de un oficio de aventureros en fase terminal porque las escuelas de periodismo y el negocio de la publicidad han extinguido la especie. Pero la vitalidad con la que todos ellos actúan hace pensar en algunos comportamientos inseparables de la profesión periodística y de su entorno. El papel de los periodistas en Primera Plana es el de privilegiados agentes y contraagentes de la lucha política y permanece en el fondo de la acción dramática" (PÉREZ, 2003: 14).

\subsection{La corrupción política y el poder de la prensa}

La obra, aunque de forma benevolente, critica a la prensa, cuyos pecados capitales se encarnan en emblema del periodismo cínico y sin escrúpulos Walter Burns. Pero, por encima de todo, Primera plana lanza un corrosivo ataque contra la clase política encarnada en la figura del alcalde de Chicago y su ayudante, el sheriff Hartman. La mezquindad de los periodistas, retratados como un grupo de holgazanes malhablados y muertos de hambre que se dedican a jugar a las cartas y a fabular noticias, que incluso ayudan a escapar a un condenado a muerte para lograr un buen titular, palidecen ante la amoralidad de los dos representantes políticos que, en su empeño por lograr un puñado de votos, tratan de ejecutar por todos los medios en víspera de las elecciones a un hombre que ya ha sido indultado.

Al igual que sucede con los periodistas y sus diarios, abundan los paralelismos de estos políticos ficticios con personajes reales de la historia de la ciudad. Las afinida- 
des entre el alcalde de Primera plana y William Hale Thompson, el regidor de Chicago entre 1915-1923 y 1927-1931, resultan desde luego inequívocas. El político republicano, famoso por su furibundo aislacionismo y su recalcitrante anglofobia, gobernó la ciudad en el periodo más violento de su historia, sumergido en una maraña de acusaciones de corrupción. Hecht describía gráficamente su gestión: "Honest Bill Thompson continues to loot the till and beam on corruption, as is the Will of the Voters" (Неснt, 1957: 35).

Si la inspiración del alcalde de la obra en el primer edil de Chicago es clara, no lo es menos la del ficticio sheriff Peter B. Hartman con Peter M. Hoffman, jefe de la policía de Chicago entre 1922 y 1926. Por su convulsa y controvertida trayectoria, buena parte de la opinión pública veía a Hoffman como un títere en manos de Capone (Hilton:2002:94). Protagonizó varios escándalos, entre ellos uno que le obligó a la paradójica situación de tener que cumplir condena en prisión cuando aún ocupaba el cargo de sheriff ${ }^{9}$. En las versiones iniciales de Primera plana figuraba además un tercer personaje del mundo de la política, un concejal de afroamericano llamado Willoughby, que en plena ley seca entraba varias veces a la sala de prensa para negociar la compra-venta de ginebra. Al igual que en los casos del alcalde y el sheriff, para los espectadores de la época también habría resultado muy fácil identificar a Willoughby con un político real, pues su figura remitía inequívocamente al político del partido republicano Oscar S. De Priest, concejal por el Segundo Distrito entre 1915 y 1917 y primer edil afroamericano en la historia de Chicago (HiLton, 2002: 35-36).

Pese a las evidentes afinidades entre Big Bill Thompson y el ficticio alcalde de Primera plana, los dardos de Hecht y MacArtur no apuntan específicamente a una persona o una sensibilidad particular, sino que más bien arremeten contra la clase política en general. La filiación del diario y de los representantes institucionales queda bastante diluida en Primera plana y en sus adaptaciones cinematográficas posteriores - en menor medida en Luna nueva-, para convertirse en una ácida crítica de la corrupción política.

Los reporteros acosan en todo momento de manera implacable a las corruptas autoridades políticas, de quienes conocen sus mezquindades y revelan sus maquinaciones. Pese a sus incontables vergüenzas periodísticas, Burns apelará a esa suprema labor para imaginar que nombrarán calles en su honor o que los exonerarán de sus condenas por todo lo que saben pero no publican. De la visión de la prensa como cuarto poder, por tanto, mana en última instancia su legitimidad y su reconocimiento social. Poco importan las bajezas en las que caigan los medios y la precariedad en la que viven los periodistas, si su pluma tiene la capacidad de desenmascarar la corrupción y castigar a los culpables.

Para CAPPABIANCA (1995: 101), la obra muestra un catálogo de instituciones prensa, política, psicoanálisis- que se comportan de modo demencial, en las que la razón ha abdicado). Para Román GuBERn (1975: 15), el microcosmos social está sazonado con la pimienta de la subversión moral, donde los dos personajes más simpá-

9 'Peter Hoffman, Ex-Coroner and Sheriff Dies', Chicago Daily Tribune, 31 de julio de 1948, p. 4. 
ticos terminan resultando el frágil condenado a muerte y la prostituta Molly, que realiza el único gesto heroico del film al lanzarse por la ventana para tratar de ayudar a Williams en su fuga.

En este ambiente de denuncia de la corrupción del stablishment y de simpatía hacia los outsiders sociales, la redención de los periodistas llega por contraste al comportamiento de los representantes políticos. Por encima de todos los errores, argucias y mezquindades de la prensa, su función de control de los excesos del poder político termina resplandeciendo, aunque los motivos por los que realice dicha función sean espurios.

"Al igual que El gran carnaval, Primera plana presenta un mundo en el que cualquiera con un cargo de poder es corrupto. Algunos reporteros le siguen haciendo el juego al statu $q u o$, pero para otros, parte del placer de ser periodista consiste en destapar la corrupción, no tanto por convicciones morales como por el hecho de que la mentira vende más ejemplares" (LALLY, 1998: 443).

También en Primera plana el inabarcable catálogo de bajezas de los periodistas encuentra su sentido por oposición a un comportamiento aún más deplorable. Si en $E l$ gran carnaval el propio Wilder ya había denunciado que el insaciable morbo de los espectadores proveía de argumentos al criminal delirio manipulador y sensacionalista de Tatum, en Primera plana las argucias de los periodistas resultan cómicas e inofensivas frente a la hipocresía, demagogia y corrupción de los representantes políticos. Tal y como apunta Hellmuth KARASEK (1993: 392), los periodistas que carecen por completo de escrúpulos son los mejores contrincantes y el mejor correctivo para políticos que carecen completamente de escrúpulos.

Tal y como acertadamente apunta RENTERO (1988: 76), no resulta casual que las únicas películas -junto con Irma, la dulce- en las que Wilder denuncia explícitamente la corrupción política y policial sean también sus dos obras sobre el periodismo. El desalmado sheriff Kretzer de El gran carnaval o su caricato colega Hartman en Primera plana invisten de autoridad la labor de los periodistas, pues son estos los únicos capaces de desentrañar la doble moral y las falsedades de sus acciones y sus discursos. En la lucha entre los poderes corruptos, la legitimación del periodismo prevalece por contraste a la superior corrupción del poder político.

\section{Conclusiones}

El crudo retrato de la privilegiada relación entre la prensa y el poder político, hilvanado en los filmes de Billy Wilder como una mutua dependencia en un contexto de corrupción, poco tiene que envidiar a las prácticas de Walter Howey en el Herald and Examiner de Hearst en el Chicago de los años veinte, probablemente la publicación más agresiva del más conocido magnate de la prensa amarilla. En el plano personal, el realizador vienés sin duda sintió muy cercana a su propia biografía la obra de Hecht y MacArthur, pues la propensión al chantaje del propietario de Kronos Verlag y jefe vienés de Wilder Imre Békessy terminó provocando su huida del país y la partida de Billie hacia Berlín.

En segundo lugar, y no por casualidad, los filmes de Wilder sobre el periodismo El gran carnaval (1951) y Primera plana (1974)- son también aquellos en los que cri- 
tica con mayor dureza la venalidad y la corrupción de la policía y del poder político. También aquí, las múltiples muestras de una actitud poco ética por parte de los reporteros se diluyen ante el abominable comportamiento de las autoridades, dispuestas en ambas películas a permitir la muerte de una persona con el objetivo de favorecer sus carreras políticas y lograr más votos.

En este contexto, la superior corrupción del poder político dota para Billy Wilder de sentido a la profesión periodística, pues son los reporteros quienes en su implacable labor de control pueden desenmascarar los abusos de las autoridades. Pese al tono satírico que adquiere la representación de los periodistas en buena parte de sus películas, todos sus pecados quedan purgados cuando logran salvar la vida de un inocente, evitar un crimen, controlar los excesos del poder político o sacar a la luz su corrupción. Si la persecución de ambiciones puramente personales conducen a Chuck Tatum a la destrucción en El gran carnaval, la actuación en última instancia como cuarto poder, tal y como sucede en Primera plana, justifica la labor de la prensa y legitima su función social.

\section{Referencias bibliográficas}

ARMSTRONG, Richard (2000): Billy Wilder. American Film Realist. Jeffeson, McFarland.

CAPPABIANCA, Alessandro (1995): Billy Wilder. Milán, Il Castoro.

COLPART, Gilles (1983): Billy Wilder. Paris, Edilig.

CROWE, Cameron (2000): Conversaciones con Billy Wilder. Madrid, Alianza.

DICK, Bernard F. (1996): Billy Wilder. Nueva York, Da Capo Press.

EHRLICH, Matthew C. (2006): Journalism in the Movies. Chicago, University of Illinois.

EMERY Michael y EMERY, Edwin (1992): The Press and America. An Interpretative History of the Mass Media. New Jersey, Prentice Hall.

FETHERLING, Doug (1977): The Five Lives of Ben Hecht. Toronto, Lester and Orpen.

FIELDING, Raymond (1957): "Time Flickers out: Notes on the Passing of the 'March of Time"'. The Quarterly of Film, Radio and Television, vol. 11, no 4, pp. 354-361.

GUBERN, Román (1975): "Billy Wilder. Un pesimista vienés en el Hollywood optimista". Dirigido por, $\mathrm{n}^{\circ}$ 21, pp. 1-15.

HEARST, William Randolph Jr. y CASSERLY, Jack (1991): The Hearst: Father and Son. Niwot, Roberts Rinehart Publishers.

HECHT, Ben (1954): A Child of the Century. New York, Simon and Schuster.

HECHT, Ben (1954): Charlie. The improbable life and times of Charles MacArthur. New York, Harper \& Brothers.

HECHT, Ben y MacARTHUR, Charles (1928): The Front Page. New York, CoviciFriede. 
HEREDERO, Carlos F. (1985): Joseph L. Mankiewicz. Madrid, Ediciones JC.

HILTON, George W. (2002): The Front Page. From Theater to Reality. Hanover, Smith and Kraus.

HUTTER, Andreas (2002): "Wie Billy Wilder zum Film-Zyniker wurde. Reporter im Wien der Inflationszeit". Jura Soyfer. Internationale Zeitschrift für Kulturwissenschaften, $\mathrm{n}^{\mathrm{o}} 2$, pp. 22-24.

HUTTER, Andreas y KAMOLZ, Klaus (1998): Billie Wilder. Eine europäische Karriere. Viena, Böhlau.

KARASEK, Hellmuth (1993): Nadie es perfecto. Barcelona, Grijalbo.

KEEFE, Rose (2003): Guns and Roses. The Untold Story of Dean O'Banion, Chicago's Big Shot Before Al Capone. Nashville, Cumberland House.

LALLY, Kevin (1998): Billy Wilder. Aquí un amigo. Barcelona, Ediciones B.

McBRIDE, Joseph (1974): "Shooting The Front Page: Two Damms and One By God" en HORTON, Robert (ed.) (2001): Billy Wilder Interviews. Jackson, University Press of Mississippi, pp. 81-88.

LESY, Michael (2007): Murder City. The Bloody Story of Chicago in the Twenties. New York, W.W. Norton \& Company.

MURRAY, George (1965): The Madhouse on Madison Street. Chicago, Follet Publishing Company.

NASAW, David (2001): The Chief: The Life of William Randolph Hearst. New York, Mariner Books.

PEÑA, Simón (2012): Caballeros de la prensa. La imagen del periodismo en el cine de Billy Wilder [Tesis doctoral]. Leioa, UPV/EHU.

PÉREZ, Xavier (2003): La comèdia de la prensa. En: HECHT, Ben y MacARTHUR, Charles: Primera plana. Barcelona, Proa.

PIZZITOLA, Louis (2002): Hearst over Hollywood: Power, Passion, and Propaganda in the Movies. New York, Columbia University Press.

RENTERO, Juan Carlos (1988): Billy Wilder. Madrid, Ediciones JC.

SALISBURY, William (1908): Career of a Journalist. New York, B.W. Dodge \& Company.

TEEL, Leonard Ray (2006): The Public Press, 1900-1945. Wesport, Praeger.

WILDER, Billy y DIAMOND, I.A.L. (1974): The Front Page [Guión definitivo]. 